\title{
INNOVATION FOR GROWTH: EVIDENCE FROM CEE EUROZONE CANDIDATES
}

\author{
Otilia Georgiana Floroiu \\ Doctoral School of Social Sciences, Stefan cel Mare University of Suceava, Suceava, \\ Romania \\ otilia.floroiu@yahoo.com
}

\begin{abstract}
This paper analyzes the European innovation framework focusing on four Eurozone candidates: Romania, Poland, Hungary, and Czech Republic. In the last decades, almost two-thirds of Europe's economic growth has been driven by innovation. This idea is supported by impressive scientific findings concerning the correlation between innovation and economic growth. We believe that better innovation performance stimulates economic convergence and in the long term, facilitates the candidates' transition towards Euro currency adoption. The countries in the study demonstrate a low innovative performance pattern, as our SWOT analysis will show. First, the gross domestic expenditure on research and development levels are far below the Union average. Secondly, there is a lack of cooperation between the academic and business sector, leading to a decreasing number of skilled personnel in the innovation industries. Lastly, these countries are suffering from an incoherent strategy aimed at reducing the productivity gap between domestic and foreign-owned firms. In order for these CEE Eurozone candidates to improve their European Innovation Score and their competitiveness, we recommend increasing investments in $R \& D$, infrastructure, education, healthcare, clean energy and shifting towards higher value-added activities. We are also suggesting supporting digital innovation hubs, the creation of new companies, and facilitating access to finance for small and medium-sized businesses.
\end{abstract}

Keywords: innovation, Eurozone, growth, CEE countries, economic convergence.

JEL classification: $011, \mathrm{O} 30, \mathrm{O} 43$.

\section{Introduction}

Currently, the EU is in the construction phase of the Economic and Monetary Union (EMU). There are $8 \mathrm{EU}$ members out of a total of 27 that don't take part in the Euro area: Bulgaria, Croatia, Czechia, Denmark, Hungary, Poland, Romania, Sweden. In order to adopt the euro currency, candidate countries must meet the Maastricht criteria designed to harmonize the national legislation with EU law and to ensure economic convergence. Adopting the euro currency is an obligation for the mentioned states (except for Denmark), however the timing depends on the national authorities. One method of postponing the transition is to avoid participation in the ERM II (Exchange Rate Mechanism), even though all the other criteria has been successfully met, as in Sweden's case. Bulgaria, Czech Republic, Poland and Hungary initially presented very ambitious time targets after joining the EU, although the Maastricht criteria was far from being met. We can see that over the years, despite the fact that their convergence positions greatly improved, the states have adopted a prudent attitude and have consistently postponed the euro adoption. Denmark is a special case as it benefits from an opt-out clause that allows them to choose between adopting the euro currency or not, but so far has proven to be reluctant to this idea given the public resistance. Economic convergence in the EMU requires the alignment of individual economic performances and therefore allows emerging economies to catch-up with developed ones, or at least reduce the existing gap. Recent evidence shows that new products and services on the market provide the highest returns and financial literature supports the premises that 
innovation generates economic growth. In return, economic growth will improve the real convergence performance of the countries and will reduce the heterogeneity degree of the eurozone. The countries selected for this comparative study are the four CEE EMU candidates: Romania, Poland, Hungary and Czechia. CEE innovative process is unique so governments should adapt innovation and technology imports to their economy's specifics.

\section{Literature review}

Innovation is a major driver of the economic progress as it generates benefits not only for consumers and businesses, but also for the economy as a whole. Innovation implies developing new ideas and technologies that lead to quality improvements for goods and services, or an increase in production efficiency.

Fundamentally, there are two methods (Rosenberg, 2004) of expanding the economic output: either by increasing the input of resources used in production, or by finding new means of production using a limited input of resources.

Even though innovation is hard to define when referring to this concept, economists (Broughel et al., 2019) usually consider a cost reduction, progress in quality, or expanding the variety of goods, services, or production methods. Innovation is considered to be an activity that produces new functions and products (Schumpeter in McDaniel, 2002) and is divided into 5 steps: introducing a new product, introducing a new method of production, opening new markets, finding more suitable sources for raw materials, and establishing a new organization within the industry.

We can analyze the concept of innovation from different perspectives (Gerguri et. Al, 2010): for the clients it means higher quality products and services, resulting in higher standards of living; for businesses it represents sustainable growth and development that lead to higher returns; for employees it translates into new, more interesting jobs that are better paid because they require extra mental efforts. Lastly, for the economy, innovation represents an increase in productivity and prosperity for all involved parties.

Innovation means more than just coming up with the newest technology. It is a phenomenon that can improve living conditions and help with community consolidation. Innovation can be technological, but also social, and the interaction between these two types can help vulnerable groups of people in ways that we could only dream of in the past (Ranchordás, 2015).

The innovative potential of an economy is influenced both by macroeconomic and microeconomic factors (Gurbiel, 2002) such as: GDP per capita, R\&D expenditures, international trade, competitiveness, technological gap, level of profit recorded by foreign companies in a country.

The European Central Bank's (ECB) interest in innovation is linked to its main objective of maintaining price stability. The financing conditions in the economy are influenced by the interest rates set by ECB, which in turn influence the general demand for goods and services in the long term. Achieving this goal depends on the long-term growth potential of the economy and, as several studies demonstrate, this is influenced by the innovative process. In order to increase innovation efficiency, the effects must diffuse throughout the entire economy and reach various industry sectors.

Diffusion of new technologies resulting from innovation can act as a powerful tool to reduce the gap in the global economy by helping countries facing difficulties to improve their living standards faster (Fagerberg et al.2010). Both in developing and developed nations, innovation is a major driver for growth and therefore it is imperative to get a better theoretical and empirical understanding of this phenomenon.

Throughout time, financial literature has shown a great interest towards studying the existing ties between innovation and economic growth. The studies will be presented based on their findings on whether there is a correlation between innovation and economic growth. 
Solow's model (1956) managed to capture the existence of a long-term relationship between the two variables using neoclassical hypotheses such as perfect competition, maximization theory, and absence of externalities._Nadiri (1993, pp.9) uses a Cobb-Douglass function to emphasize the connection between innovation, turnover and productivity increase.

Ulku's analysis (2004, pp. 13) is based on 20 OECD members and 10 non-OECD members and uses the panel model presented by Romer (1986, pp. 1014). In conclusion, the research shows that between 1981-1997, innovation has had a positive effect on GDP per capita both for developed and developing economies.

According to Pece et al. (2015, pp. 466) innovation and investments in R\&D and technology are responsible for driving competitiveness, progress, as well as a sustainable economic growth rate. The variables used to represent innovation in the multiple regression models applied on CEE countries are number of patent applications, number of trademarks, and $R \& D$ expenditures. The results show the existence of a positive relationship between economic growth and innovation.

Kelly's (2018, pp. 25) research shows that periods of time with high numbers of patent applications are followed by high productivity cycles.

The bidirectional causality between innovation and economic growth is demonstrated by Pradhan et al. (2016, pp. 5) and analyzed by Maradana et al. (2017, pp. 9) in a complex study focused on 19 European countries during 1989 and 2014, using the Granger Causality test. The study showed that in Denmark, Finland, Ireland, The Netherlands, Norway, Poland, and Spain per capita economic growth determines innovation. In Romania, a bidirectional causality between innovation and economic growth is manifested, whereas in Sweden and Greece, per capita economic growth does not influence innovation. The authors recommend that in order to promote per capita economic growth, the economists must pay more attention towards innovation policy strategies. Given the bidirectional causality, governments should also consider the fact that through a GDP per capita increase, the innovation process will be stimulated. It is advisable that the role of the government should also focus on hosting innovation and integrating it in the per capita economic growth.

The impact of innovation on economic growth on the Nigerian market is examined by lyoboyi \& Na-Allah (2014, pp.45) between 1970-2011 using the OLS dynamic method of research that shows the existence of a balanced long-term relationship between the dependent variable (economic growth) and the most significant variable of interest (innovation).

The technology spillover effect (Cameron, 1998) reduces the cost of competitors and leads to imperfect patents and movement of skilled labor force to other companies. The failure of companies to acquire all the social gains generated by innovation can lead to the widening of the performance gap. The replacement effects generated by innovation imply that new ideas will make the current production methods outdated.

Petrariu et al. (2013, pp. 20) analyzes the case of 15 states: Estonia, Latvia, Lithuania, Poland, Germany, Czechia, Slovakia, Romania, Hungary, Moldova, Bulgaria, Croatia, Macedonia, and Serbia between 1996 and 2010. The researchers reached the conclusion that an economically developed state will invest more in research and this will lead to an innovation increase. R\&D expenditures and the number of patents have a negative impact on economy growth due to the existence of a catch-up process. Through innovation, countries can reduce the existing gap between emerging and developed economies.

Pessoa (2007, pp. 14) chose Sweden and Ireland for his research and concluded that there is no strong relation between R\&D spending and economic growth. The recommendations mention including other markers for innovation in the research, not only $R \& D$ expenditures. Inekwe (2014, pp. 15) developed a study focused on 66 developing economies between 2000 and 2009. The countries were divided into two groups: upper-middle-income economies and lower-middle-income economies. The study concludes that R\&D investments have a significant impact on economic growth in developing countries. There is 
a positive impact on economic growth in upper-middle-income countries, whereas in countries with low income the impact is insignificant.

Tuna et al. (2015, pp. 506) ran the Johansen Cointegration test and Granger Causality test on data collected from Turkey between 1990 and 2013. The results showed that there is no evidence of a long-term connection between real R\&D expenses and the economic growth series. This could be due to the fact that Turkey is considered to be a developing country, where significant investments into R\&D have been made in the past decades. However, the benefits won't be visible in the economy for the next 20 to 35 years.

Silaghi et al. (2014, pp. 110) used a dynamic panel model to explore the existing relationship between public and private R\&D spending and economic growth. The findings showed that an increase of $1 \%$ in private R\&D spending will result in a $0,2 \%$ increase in economic growth, concluding that the relation is not significant.

Another research paper that focused on emerging countries was carried out by Vuckovic (2016, pp. 2) during 1991 and 2013. Results show that there is no statistical relationship between economic growth (GDP growth rate) and innovation (number of patent applications per million population). Another finding of the study investigates the negative impact that foreign direct investments have on the number of patent applications. Multinational companies, who represent the main foreign direct investors in the economy, reduce the number of patent applications by transferring know-how in the emerging economies.

Countries that fail at implementing sensible innovative policies are at risk of experiencing the reality of global innovative arbitrage (Thierer, 2016). The innovation process wanders the same way capital moves around the world, in search of the highest returns. The innovationists can, and many actually do so, move to states or continents that pride themselves on supporting entrepreneurial activity in a legal and regulatory environment.

A good example (Andreessen, 2014) to support the above mentioned is what happened to Amazon in the US, at the end of 2013. The company was interested in using drones for faster package delivery, but before the testing phase began it encountered strict policies imposed by the Federal Aviation Administration and decided to move its R\&D and operational testing to UK and Canada.

There are several authors (Ford, 2015 and Wallach, 2015) that underrate the innovation effects on technology and focus on the disruptive effects linked to changes in the technological environments.

\section{Innovation in Europe: a comparison across four CEE Eurozone candidates}

Even though Europe has a great innovative potential, the growth process is still laborious. The slow innovation diffusion intensifies the existing difference in productivity between the most and the least productive companies.

The European Innovation Scoreboard (EIS) offers a comparative analysis of the performance in Research \& Development (R\&D) and emphasizes the strengths and threats faced by the national innovation systems.

According to the 2019 EIS Report, EU innovation performance has grown on average by $8.8 \%$ since 2011 , as a result of the strong performance of 25 member states, while Romania decreased by $10.7 \%$ in the same period. The fastest-growing performers are Lithuania, Greece, Latvia, Malta, Estonia, and the Netherlands. The report also shows that the convergence process, which allows lower performing countries to grow at a faster rate than higher performing countries, has speeded up in the EU in 2018.

According to EIS 2019, it was the fourth consecutive year of growth in Europe. Based on performance, the innovation categories are innovation leaders, strong innovators, moderate innovators, and modest innovators. 
Poor results are registered in Bulgaria (48.72) and Romania (34.13), where performances were below $50 \%$ of the European average. Sweden is the 2019 EU innovation leader (147.74 out of a maximum of 150), followed by Finland, Denmark, and the Netherlands.

\section{EUROPEAN INNOVATION SCOREBOARD RATINGS 2019}

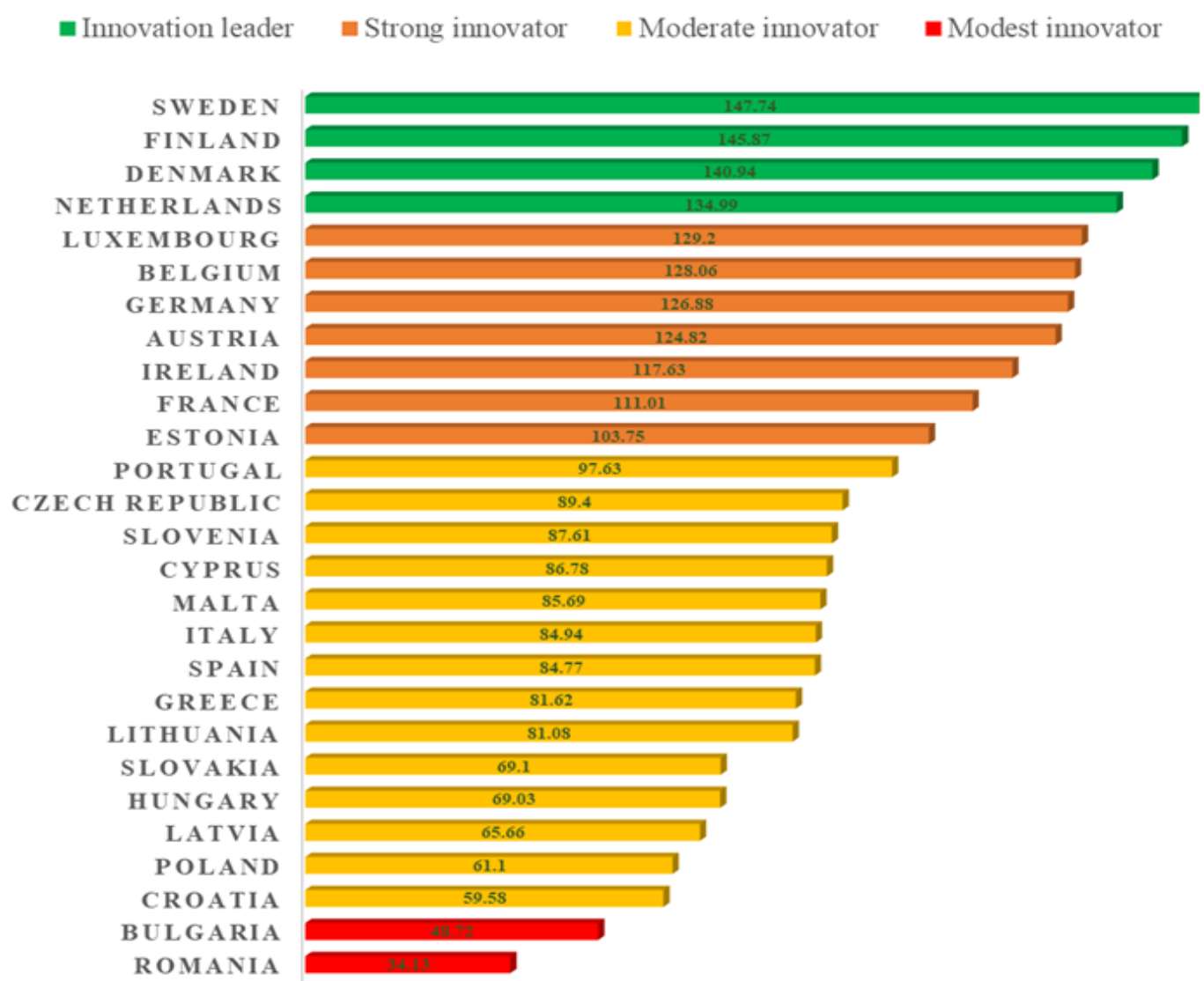

Figure 1: European Innovation Scoreboard Ratings 2019

Source: Own computation based on European Commission data.

The four countries selected for the comparative study are all CEE EMU candidates: Romania (rank 28), Poland (rank 25), Hungary (rank 23) and Czechia (rank 14). With the exception of Romania, all the other countries are moderate innovators. The same hierarchy is followed by the R\&D expenditure as a percentage of GDP. The increase between 2014 and 2018 registered in Romania (target 2\%), Poland (target $1.7 \%$ ), and Hungary (target $1.8 \%$ ) is not enough, as the countries are still far from reaching the imposed target. Czechia has cut back on R\&D expenditure, but the $1 \%$ target is still achieved. 


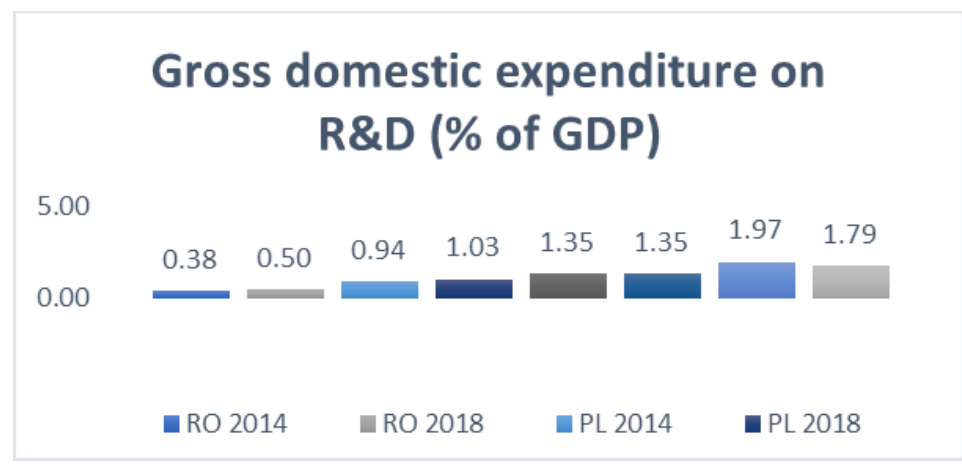

Figure 2: Gross domestic expediture on R\&D in Romania, Poland, Hungary and Czechia (\% of GDP) in 2014 and 2018

Source: Own computation based on European Commission data.

The performance relative to EU in 2011 analysis shows that, although after 2011 there was a decrease in innovation, all the states except for Romania managed to reach a higher score in 2018 compared 2011.

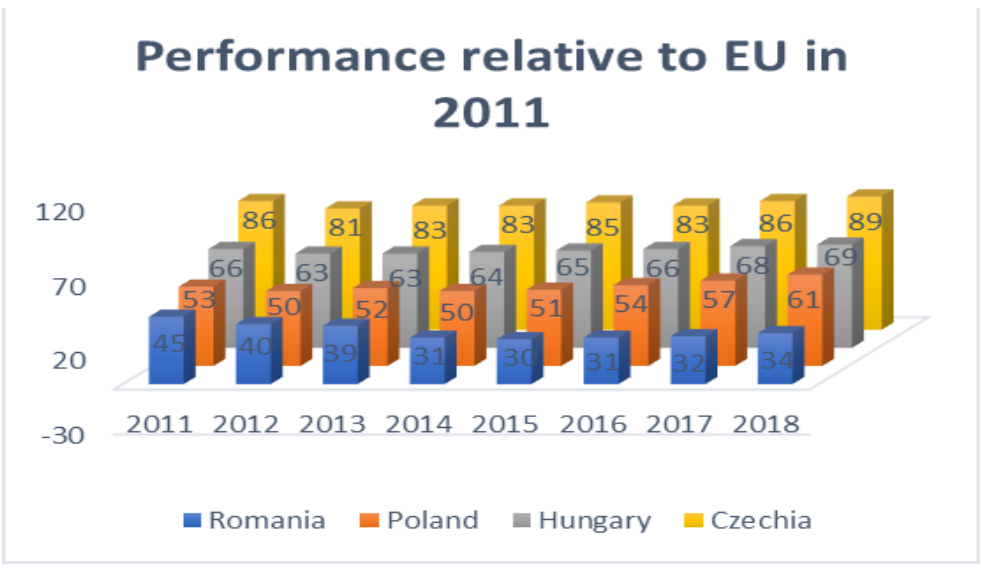

Figure 3: Performance relative to EU in 2011 between 2011-2018 for RO, PL, HU, CZ. Source: Own computation based on European Commission data.

By analyzing each country's profile, we can better understand the measured results and issue some future recommendations. In order to do so we have created individual SWOT analyses.

The lack of innovation has placed Romania last in the EU and this statistic has worsened since 2010. Public investment in R\&D is the lowest in the EU (0.5\% of GDP) and public R\&D expenditure has declined from $0.32 \%$ of GDP in 2011 to $0.21 \%$ of GDP in 2017.

Some innovation deficient areas are number of $\mathrm{PhD}$ graduates, opportunity-based entrepreneurship, risk capital expenditure, and available human resources. Strongest innovation markers are broadband penetration and medium and high-tech product exports. 


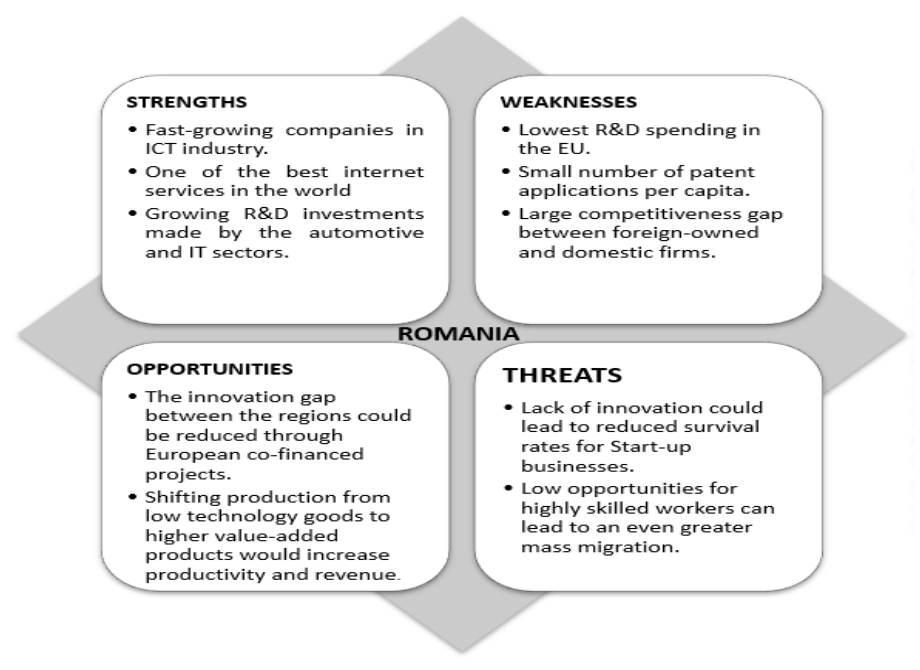

Figure 4: Innovation SWOT analysis for Romania

Source: Own computation based on European Commission data.

Poland's strong economic performance from the past decade has been fueled by the manufacturing and export of relatively low-technology products. The need for investments in technology is pressing, as the population is aging, and the retirement age was reduced. Gross domestic expenditure on $R \& D$ level barely reaches half of the European average.

Overall, Poland is currently ranking well under the EU average when it comes to innovation and productivity, much like its Eastern European neighbors. However, recent legal efforts to address these issues along with an increase in financing for the academic community should have a positive effect in the years to come.

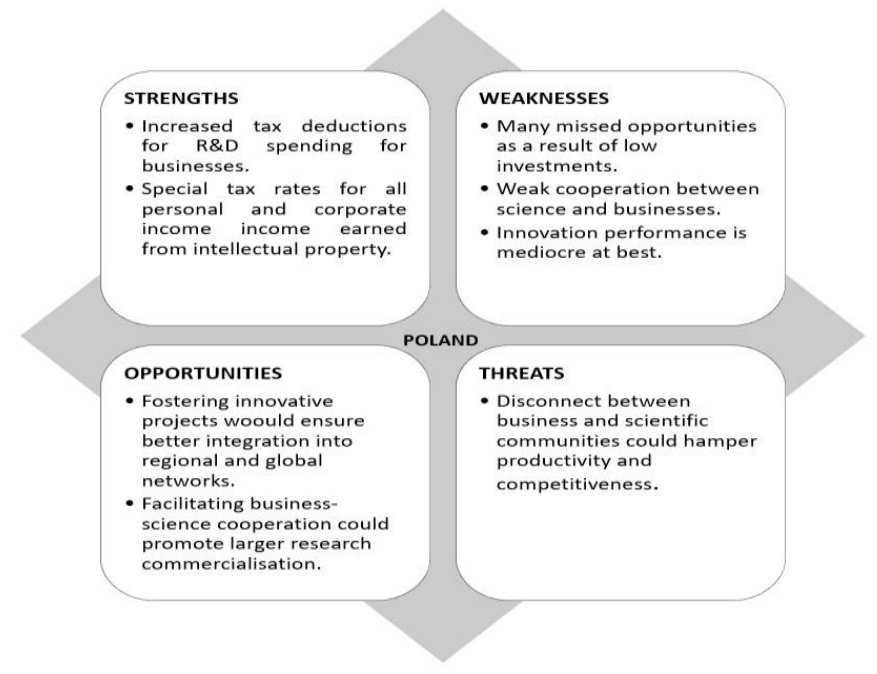

Figure 5: Innovation SWOT analysis for Poland Source: Own computation based on European Commission data. 
Innovation has been declining Hungary when compared to other countries in the European Union. Just like Romania, Hungary displays an insignificant entrepreneurial culture with few patent applications and not many innovative businesses shifting towards globalizing.

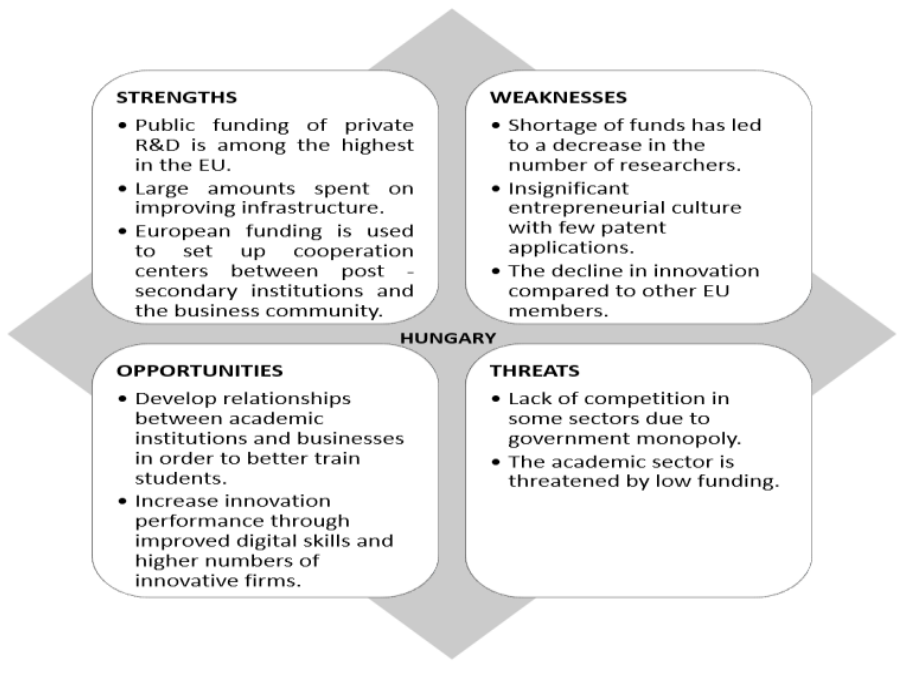

Figure 6: Innovation SWOT analysis for Hungary

Source: Own computation based on European Commission data.

The Czech Republic is performing far better than its Eastern European peers when it comes to innovation and productivity, although there is lots of room for improvement. The economy of the Czech Republic is mainly dominated by manufacturing and further investments in education need to be made in order to prepare the population for technological advancements the future will bring. The country is a moderate innovator, scoring just about average at EU levels despite the significant increase in R\&D intensity, mainly funded through European capital.

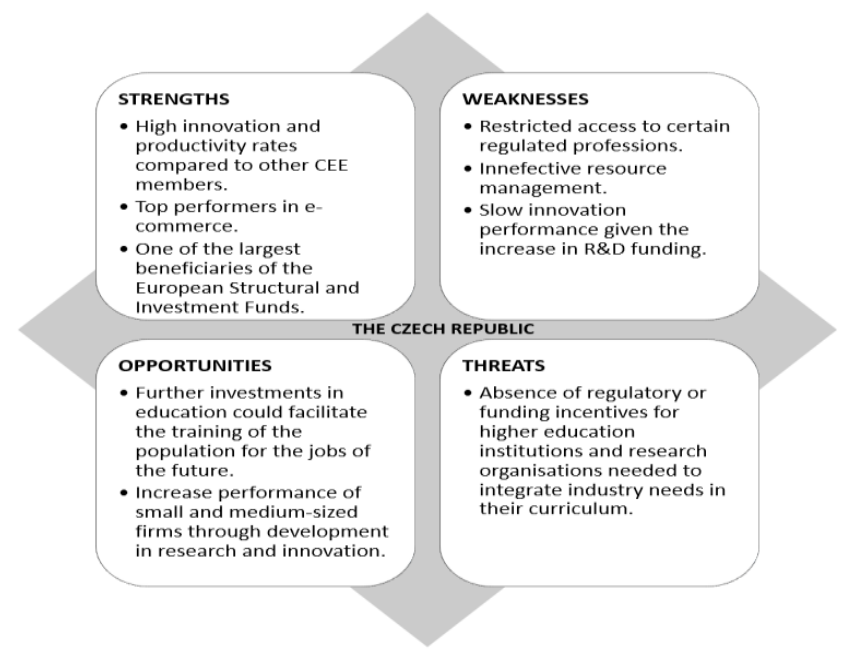

Figure 7: Innovation SWOT analysis for Czech Republic

Source: Own computation based on European Commission data. 


\section{Conclusions}

Innovation is a powerful engine for driving economic growth, while also facilitating the creation of better paid jobs.

The European Innovation Scoreboard provides a comparative analysis of innovation performance for EU states and examines the strengths and weaknesses of national innovation systems. According to EIS 2019, Romania is a modest innovator and remains the EU member state with the lowest innovation score. The ranks for the four countries selected for the comparative study are: Romania (rank 28), Poland (rank 25), Hungary (rank 23) and Czechia (rank 14).

Even though we notice similar patterns causing innovation to stagnate in the four countries analyzed, we also believe that there are plenty of opportunities for development in the years to come, such as supporting creation of Start-ups, providing better access to financing instruments for small and medium-sized businesses, and reducing the innovation gap at a sub-national level. A strength that stands out is the improvement of legislation benefiting companies that engage in R\&D activities. The most significant weakness is the lack of a strong relationship between the academic and business communities. The countries are threatened by a large productivity gap between domestic and foreign-owned businesses.

Although this is a highly debated matter, we believe there is a strong correlation between innovation and economic growth, as demonstrated by several studies presented in the Literature review section. We can therefore consider that innovation leads to an increase in GDP per capita and helps countries improve their real convergence. Romania and the other candidates would benefit from increased investments in innovation that would support the economic convergence requested by EMU.

\section{References}

Andreessen, M., 2014. Turn Detroit into Drone Valley. Politico, Available at: https://www.politico.com/magazine/story/2014/06/turn-detroit-into-drone-valley-107853, [accessed 14.12.2019].

Broughle, J., Thierer, A., 2019. Technological innovation and economic growth: $A$ brief report on the evidence. Mercatus Center, George Mason University [online], Available at: https://www.mercatus.org/system/files/brougheltechnological-innovation-mercatus-researc h-v1.pdf, [accessed 11.11.2019].

Cameron, G., 1998. Innovation and growth: a survey of the empirical evidence. Working Paper, Nuffield College, Oxford, pp. 1-34, Available at: https://pdfs.semanticscholar.org/ba6b/ d52fb55d3e6d6f4566c974895220526ac6f0.pdf, [accessed 14.12.2019].

European Commission, 2019. European Innovation Scoreboard. Available at: https://ec.europa.eu/growth/industry/innovation/facts-figures/scoreboards en, [accessed 10.10.2019].

Fagerberg, J., Verspagen, B., Srholec, M., 2010. Innovation and Economic Development. Handbook of the Economics of Innovation [online], Volume 2, pp. 833-872, North Holland, Available at: www.sciencedirect.com/science/article/pii/S0169721810020046?via\%3Dihub. Ford, M., 2015. Rise of the Robots: Technology and the Threat of a Jobless Future. Basic Books, Available at: https://www.uc.pt/feuc/citcoimbra/Martin Ford-Rise of the Robots.

Gerguri, S., Ramadani, V., 2010. The Impact of Innovation into the Economic Growth. Munich Personal RePEc Archive [online], Paper No. 22270, Available at: https://mpra.ub.uni-muenchen.de/id/eprint/22270, [accessed 05.01.2020].

Gurbiel, R., 2002. Impact of innovation and technology transfer on economic growth: The Central and Eastern Europe Experience. Warsaw School of Economics [online], pp. 1-18, Available at: https://www.eadi.org/typo3/fileadmin/WG Documents/Reg WG/ gurbiel.pdf, [accessed 16.01.2020]. 
Inekwe, J. N., 2014. The Contribution of R\&D Expenditure to Economic Growth in Developing Countries. Social Indicators Research, pp. 1-19, Available at: https://www.jstor.org/stable/24721667, [accessed 15.12.2019].

lyoboyi, M., Na-Allah, A, 2014. Innovation and economic growth: evidence from Nigeria. EuroEconomica [online], 33, 1 (1), pp. 1582-8859, Available at: http://journals.univ-danubius.ro/index.php/euroeconomica/article/view/2330/3163,

[accessed 14.12.2019].

Kelly, B., Papanikolaou, D., Seru, A., and Taddy M., 2018. Measuring Technological Innovation over the Long Run. NBER Working Paper [online], No. 25266, Available at: https://www.nber.org/papers/w25266.pdf, [accessed 02.12.2019].

Maradana, R. P, Pradhan, R. P., Dash, S., Gaurav, K., Jayakumar, M., and Chatterjee, D., 2017. Does innovation promote economic growth? Evidence from European countries. Journal of Innovation and Entrepreneurship [online], Springer, 6 (1), pp. 1-23, Available at: http://link.springer.com/10.1186/s13731-016-0061-9.

Nadiri, I.,1993. Innovations and Technological Spillovers. NBER Working Papers 4423 [online], National Bureau of Economic Research, Cambridge, MA, Available at: http://www.nber.org/papers/w4423.pdf, [accessed 10.12.2019].

Pece, A.M., Simona, O.E., Salisteanu, F., 2015. Innovation and economic growth: An empirical analysis for CEE countries. Procedia Economics and Finance 26 [online], pp. 461 - 467, Available at: https://www.sciencedirect.com/science/article/pii/S2212567115008746. Pessoa, A., 2007. Innovation and Economic Growth: What is the actual importance of R\&D?. FEP Working Papers [online], no. 254, pp. 1-17, Available at: https://www.researchgate.net /publication/24111638 Innovation and Economic Growth

What is the actual importance of RD, [accessed 10.11.2019].

Petrariu, I.R., Bumbac, R., Ciobanu, R., 2013. Innovation: a path to competitiveness and economic growth. The case of CEE countries. Theoretical and Applied Economics [online], XX, 5 (582), pp. 15-26, Available at: http://store.ectap.ro/articole/857.pdf.

Pradhan, R. P., Arvin, M. B., Hall, J. H., and Nair, M., 2016. Innovation, financial development and economic growth in Eurozone countries. Applied Economics Letters [online], 23(16), pp. 1141-1144, Available at: https://repository.up.ac.za/handle/2263/57404.

Ranchordás, S., 2015. Does Sharing Mean Caring? Regulating Innovation in the Sharing Economy. Minnesota Journal of Law, Science \& Technology [online], Available at: http://wpressutexas.net/cs378h/images/5/57/Does Sharing Mean Caring.pdf.

Romer, P.M., 1986. Increasing Returns and Long-Run Growth. The Journal of Political Economy [online], 94, pp. 1002-1037, Available at: http://www.dklevine.com/archive/refs42232.pdf, [accessed 11.11.2019].

Rosenberg, N., 2004. Innovation and economic growth. Organization for Economic Co-operation Development. [online] Available at: https://www.oecd.org/cfe/tourism/ 34267902.pdf, [accessed 05.01.2020].

Schumpeter, J., in McDaniel, B. A., 2002. Entrepreneurship and Innovation: An Economic Approach, M.E Sharpe, pp. 57-58, Available at: https://content.taylorfrancis.com/books/ download?dac=C2014-0-39866-3\&isbn=97813174 71387\&format=googlePreviewPdf.

Silaghi, M. I. P., Alexa, D., Jude, C., and Litan, C., 2014. Do Business and Public Sector Research and Development Expenditures Contribute Economic Growth in Central and Eastern European Countries? A Dynamic Panel Estimation. Economic Discussion Papers 2012-4 [online], pp. 108-119, Available at: https://ideas.repec.org/p/ris/kngedp/ 2012 004.html, [accessed: 17.12.2019].

Solow, R., 1956. A Contribution to the Theory of Economic Growth. The Quarterly Journal of Economics [online], 70 (1), pp. 65-94, Available at: http://piketty.pse.ens.fr/ files/Solow1956.pdf, [accessed 08.11.2019]. 
Thierer, A., 2016. Innovation Arbitrage, Technological Civil Disobedience \& Spontaneous Deregulation. Technology Liberation Front, Available at: https://medium.com/tech-liberation/innovation-arbitrage-technological-civil-disobedience-sp ontaneous-deregu lation-eb90da50f1e2, [accessed 15.01.2020].

Tuna, K., Kayacan, E., Bektas, H., 2015. The Relationship Between Research \& Development Expenditures and Economic Growth: The Case of Turkey. Procedia - Social and Behavioral Sciences [online], 195, pp. 501 - 507, Available at: https://www.sciencedirect.com/science/article/pii/S1877042815037349?via\%3Dihub.

Ulku, H., 2004. R\&D, Innovation, and Economic Growth: An Empirical Analysis. International Monetary Fund Working Papers [online], WP/04/185, pp. 2-35, Available at: https://www.imf.org/en/Publications/WP/lssues/2016/12/30/R-D-Innovation-and-EconomicGrowth-An-Empirical-Analysis-16927, [accessed 11.11.2019].

Vuckovic, M., 2016. The relationship between innovation and economic growth in emerging economies. Forschungsforum der Osterreichischen Fachhochschulen [online], Available at: http://ffhoarep.fh-ooe.at/bitstream/123456789/738/1/130_323_Vuckovic_ FullPaper_en_Final.pdf, [accessed 12.11.2019].

Wallach, $\bar{W}$., 2015 . A Dangerous Master: How to Keep Technology from Slipping beyond Our Control. Basic Books.

\section{Bio-note}

Otilia Floroiu is a PhD student in fifth year of study at Stefan cel Mare University of Suceava and is currently working on her PhD thesis: "Efficient Strategies for the Euro Currency Adoption in Romania". 